\title{
RANCANG BANGUN TEKNOLOGI MODIFIED ATMOSPHERE STORAGE (MAS) DENGAN KAPASITAS 4,77 $\mathrm{m}^{3}$
}

\author{
Wina Libyawati ${ }^{1, *}$, Agri Suwandi ${ }^{1}$, Hafidan Agustian ${ }^{1}$ \\ ${ }^{1}$ Jurusan Teknik Mesin, Fakultas Teknik, Universitas Pancasila, Jakarta, Indonesia \\ Srengseng Sawah Jagakarsa, 12640 \\ *Email : wina@univpancasila.ac.id
}

\begin{abstract}
ABSTRAK
Pola hidup sehat berbasis makanan teknologi olah minimal diterapkan oleh masyarakat untuk meningkatkan kualitas kesehatan. Teknologi olah minimal dipergunakan untuk memperlambat laju pembusukan makanan sewaktu di ruang penyimpanan. Teknologi olah minimal terdiri dari Controlled Atmosphere Storage (CAS), Modified Atmosphere Storage (MAS), Freeze Drying, dan Blansir. MAS adalah teknologi penyimpanan makanan dengan pengkondisian kadar oksigen di ruang simpan. Salah satu bahan makanan yang diterapkan pada MAS adalah buah pisang, karena pisang merupakan buah yang tidak mengenal musim tetapi memiliki umur penyimpanan yang pendek. Gas Injector yang digunakan adalah venture sparger. Rancang bangun teknologi MAS menggunakan metode Ulrich dan Eppinger dan dilanjutkan proses pembuatan komponen komponen teknologi MAS. Pembuatan komponen dan perancangan teknologi MAS dihitung berdasarkan Design for Manufacturing and Assembly (DFMA) untuk menghitung biaya yang dibutuhkan. Tujuan penelitian ini adalah teknologi MAS mampu menyuntikan karbon dioksida serta menurunkan oksigen hingga dibawah 10\%. Penyuntikan karbon dioksida dilakukan dengan debit 5 liter per menit yang disuntikkan melalui sparger. Hasil pengujian menunjukkan penurunan kadar oksigen sampai 8,5\% dalam waktu penyuntikan karbon dioksida selama 24 jam. Hasil uji buah pisang di laboratorium analisa makanan memiliki kadar glukosa 5,33\%, sementara kadar glukosa untuk pisang yang matang adalah di atas $10 \%$.
\end{abstract}

Kata kunci: Perancangan, Sparger, Pengawetan, Buah, MAS

\begin{abstract}
Healthy life style based on the principle of minimally processing food, has been implemented by the people, in order to increase their health. Minimally processing application is to slow down the decay rate at the storage room. Minimally processing is consists of Controlled Atmosphere Storage (CAS), Modified Atmosphere Storage (MAS), Freeze Drying, and Blanching. MAS are storage method by modifying the oxygen level in the storage room. An example of MAS application in fruit is banana, due to its advantage as the all session fruit yet having such a short life time. Venture sparger is the main component in MAS, which has a function as gas injector. MAS embodiment is using Ulrich and Eppinger design method, and manufacturing of MAS components. The manufacturing cost estimation of MAS is using Design for manufacturing and assembly (DFMA). The purpose of this research is MAS prototype able to modified the oxygen level in the storage room below 10\%, by injecting carbon dioxides. Carbon dioxides are injected by sparger with a set debit at 5 liters per minute. The experimental results shown that MAS able to modified the oxygen level to $8.5 \%$ within 24 hours and the banana in MAS has $5.3 \%$ glucose level, while the maturity level of banana is above $10 \%$.
\end{abstract}

Keywords: Design, Sparger, Preservation, Fruit, MAS 


\section{PENDAHULUAN}

Kesadaran masyarakat dalam mengkonsumsi makanan bergizi semakin meningkat, hal tersebut mengakibatkan adanya gerakan back to nature dan meningkatnya permintaan terhadap produk pangan tanpa banyak pengolahan atau disebut teknologi olah minimal. Teknologi olah minimal diterapkan pada buah-buahan dan sayuran. Teknologi olah minimal bekerja dengan memaksimalisasi proses biologis sehingga tidak merusak nilai gizi bahan makanan tersebut.

Penerapan pengawetan makanan dengan olah minimal telah diteliti diantaranya adalah: perkembangan teknologi olah minimal dengan pemanfaatan keemasan menggunakan gas seperti oksigen, karbon dioksidan dan nitrogen (Sandhya, 2010); model matematika untuk memprediksi molekul oksigen, karbon dioksida dan temperature untuk MAS di dalam kemasan strawberries selama penyimpanan dengan kondisi temperatur yang berubah-ubah. Model matematika dibuat berdasarkan data eksperimental penyimpanan strawberries dan data numerical, hasil model matematika menunjukkan bahwa prosentase kadar gas oksigen dan karbon dioksida merupakan parameter penting dalam MAS (Barrios.S, 2014); eksperimental dampak penggunaan MAP pada bayam, dengan tiga variasi temperatur $\left(5^{\circ} \mathrm{C}, 10{ }^{\circ} \mathrm{C}, 20^{\circ} \mathrm{C}\right.$, dan $\left.25^{\circ} \mathrm{C}\right)$ terhadap massa dan kandungan klorofil pada bayam, hasil eksperimental menunjukkan bahwa penurunan klorofil terjadi seiring dengan peningkatan temperatur (Zenoonzian, 2011); perkembangan MAP untuk keju dengan mengendalikan komposisi kandungan gas karbon dioksida dan kombinasi gas karbondiosida-nitrogen-oksigen dalam ruang simpan, dengan melihat hasilnya dari $\mathrm{pH}$, kelembapan, dan perubahan massa dari keju (Sadegh Khoshgozaran, 2012); review penerapan MAP pada hasil panen buah dan sayuran terhadap kandungan mikroba selama penyimpanan telah dilakukan untuk menjamin tingkat kesegaran dan kualitas dari hasil panen (Oluwafemi J. Caleb, 2013); experimental pemanfaatan MAS untuk peningkatan waktu simpan paprika dengan mengatur temperatur dan kelembaban relatif dalam kotak steoreofoam (D.V, 2013); Penentuan waktu simpan blueberries dengan metode controlled atmosphere storage(CAS) dan ozonisasi untuk blueberries dengan hasil metode ozonisasi lebih efektif untuk memperlambat pertumbuhan jamur dan pembusukan (Anibal Concha-Meyer, 2015); review pengembangan MAP untuk buah dan sayur dengan memvariasikan material penyimpanan dengan melihat kandungan oksigen dan karbondioksida (Mahmoud Soultani, 2015); analisis dan optimasi dari sparger untuk karbon dioksida dilakukan pada instalasi pembuatan minuman dengan variasi sparger dibantu dengan simulasi CFD (Massimiliano Rinaldi, 2016).

pada proses penyimpanan dengan pengkondisian udara sekitar seperti teknologi vakum pada hasil panen padi (Sidik, 2000), teknologi Controlled Atmosphere Storage (CAS (Kader, 2004) serta teknologi Modified Atmosphere Store (MAS) (Rohani, Zaipun, \& Norhayati, 1997; Sudiari \& Sutrisno, 1998) Teknologi penyimpanan vakum dimulai dengan pembuatan ruang penyimpanan berkapasitas $1000 \mathrm{~kg}$ dengan dimensi $100 \mathrm{~cm} \mathrm{x}$ $100 \mathrm{~cm} \times 120 \mathrm{~cm}$, dinding berbahan plastik tahan temperatur $\left(-60{ }^{\circ} \mathrm{C}\right.$ sampai $\left.60{ }^{\circ} \mathrm{C}\right)$ dengan tebal 1-3 mm. Ruangan selanjutnya ditambahkan vakum untuk menghisap oksigen di dalamnya (Sidik, 2000).

Metode-metode teknologi olah minimal sebagai berikut teknologi vakum, yaitu teknologi penyimpanan bahan makanan dengan cara menurunkan kadar oksigen pada air hingga di bawah 2\%. (Sidik, 2000). Teknologi Controlled Atmosphere Storage (CAS) tidak hanya mengendalikan kadar oksigen saja, dengan mengontrol keadaan udara normal $78 \% \mathrm{~N}_{2}, 21 \% \quad \mathrm{O}_{2}$, dan $0,03 \%$ $\mathrm{CO}_{2}$ menjadi oksigen di bawah $8 \%$ dan karbondioksida di atas 1\%. (Kader, 2004). Selain pada pengendalian kadar gas ruang, teknologi olah minimal dapat juga dilakukan dengan metode mengatur suhu ruang simpan di bawah $10{ }^{\circ} \mathrm{C}$ akan memperpanjang masa penyimpanan buah pepaya hingga 6 minggu (Rohani, Zaipun, \& Norhayati, 1997). Sedangkan penelitian yang dilakukan oleh $\mathrm{Ni}$ Made Sudiari dan Sutrisno (Sudiari \& Sutrisno, 1998) dengan teknologi Modified Atmosphere Storage (MAS) dengan ruang simpan di bawah $5{ }^{\circ} \mathrm{C}$ pada penyimpanan buah nangka akan memperpanjang masa simpan hingga 16 hari. Teknologi CAS telah dipatenkan oleh Badran dengan melakukan penyimpanan buah pisang pada ruang 
penyimpanan dengan temperatur $15.56{ }^{\circ} \mathrm{C}$ dan $21,11{ }^{\circ} \mathrm{C}$ dan dilakukan selama 30 hari untuk melihat perubahan pada kualitas pisang (M, 1969).

Metode-metode yang disebutkan bertujuan untuk mengawetkan bahan makanan dengan menggunakan teknologi olah minimal agar tidak menurunnya nilai gizi yang terkandung bahan makanan. Bahan makanan yang disimpan dalam teknologi olah minimal akan memiliki masa ketahanan yang lebih lama baik dalam segi rasa, warna, dan aroma. Namun, keseluruhan metode dan teknologi olah minimal makanan berfokus kepada pengawetan di tahap proses penyimpanan. Perwujudan rancang bangun dilakukan dengan menerapkan prinsip-prinsip perancangan Ulrich dan Eppinger (Ulrich \& Eppinger, 2008).

\section{a. Penyimpanan Bahan Makanan}

Penyimpanan bahan makanan ditujukan untuk memperpanjang shelf life dengan memperlambat laju pembusukan makanan tersebut. Pembusukan makanan dipengaruhi berbagai faktor yaitu suhu, kelembaban, kadar udara, cahaya, waktu, dan faktor dari luar seperti adanya mikro organisme. Proses penyimpanan konvensional seperti penyimpanan pada lumbung, lemari, dan kulkas tidak memberikan pengaruh besar pada umur ketahanan makanan, bahkan menyebabkan timbulnya bau tak sedap. Berbagai teknologi dikembangkan yang ditujukan untuk memperpanjang shelf life makanan (Sari \& Hadiyanto, 2013).

\section{b. Teknologi Modified Atmosphere Storage}

Proses respirasi dan tanda-tanda pemotongan dapat dihambat jika buah dan sayuran agar disimpan dalam atmosfer yang mengandung $\mathrm{CO}_{2}$ tinggi dan $\mathrm{O}_{2}$ rendah dibandingkan udara normal. Controlled Atmosphere Storage (CAS) merupakan teknologi penyimpanan buah atau sayur segar dalam atmosfer (udara) yang mengandung komposisi $\mathrm{CO}_{2}$ tinggi dan $\mathrm{O}_{2}$ rendah dengan kondisi dipertahankan secara konsisten. Modified Atmosphere Storage (MAS) merupakan teknologi penyimpanan buah atau sayur segar dalam atmosfer (udara) dengan menggunakan komposisi $\mathrm{CO}_{2}$ yang tinggi dan komposisi $\mathrm{O}_{2}$ yang rendah dan telah diatur pada awal penyimpanan, atau tidak diatur sama sekali atau digunakan kemasan/film tertentu yang dapat mengatur sendiri komposisi udara di dalamnya. Penyimpanan hipobarik adalah cara penyimpanan $C A S$ yang dikondisikan dengan cara menurunkan tekanan udara yang dikombinasikan dengan suhu rendah.

\section{c. Pengaruh Oksigen dan Karbondioksida Terhadap Mutu Buah}

Pengaruh penyimpanan buah atau sayur segar dalam atmosfer dengan komposisi $\mathrm{CO}_{2}$ tinggi dan $\mathrm{O}_{2}$ rendah antara lain dapat menyebabkan respirasi terhambat; asam tertimbun; pembentukan asetaldehida; peningkatan jumlah gula; penurunan jumlah zat yang larut dalam alkali; jumlah pektin total tinggi; dan proses perombakan klorofil dihambat. Respirasi terhambat karena ketersediaan $\mathrm{O}_{2}$ rendah dan $\mathrm{CO}_{2}$ tinggi, hal ini mengakibatkan pematangan dapat dihambat sehingga umur penyimpanan buah dan sayur dapat lebih lama. Proses penimbunan asam yang terjadi akibat respirasi menurun, peningkatan penambahan $\mathrm{CO}_{2}$ atau enzim menjadi tidak begitu aktif.

Akibat buruk penyimpanan karena komposisi atmosfer yang tidak tepat atau kemasan yang tidak baik membuat perubahan warna daging buah, perubahan citarasa, gagal matang, penimbunan asam organik dan kerusakan jaringan. Sedangkan dengan tingginya konsentrasi dapat $\mathrm{CO}_{2}$ menyebabkan penurunan reaksi sintesis pematangan; penghambatan beberapa kegiatan enzimatik; penurunan produksi zat atsiri/aroma; penimbunan asam organik; kelambatan pemecahan pektin; penghambatan sintesis klorofil dan penghilangan warna hijau; perubahan perbandingan berbagai gula; produksi bau dan rasa yang tidak dikehendaki; kenaikan $\mathrm{pH}$ penurunan asam askorbat; perubahan warna daging buah; pertumbuhan jamur terhambat; dan menghambat peran etilen (C2H4). Kondisi penyimpanan (CO2, O2) masing-masing komoditas berbeda-beda. (Ariyanto, Arifin, \& Ilyas, 2011).

\section{d. Sparger}

Sparger adalah alat pemecah gelembung-gelembung udara agar gelembung udara yang terbentuk berukuran kecil sehingga luas permukaan interfasanya lebih besar sehingga laju difusi oksigen ke dalam larutan cepat. Sparger dibagi dengan 3 jenis yaitu 
sparger berpori (untuk pencampuran berskala laboratorium tanpa agitator), spargerorifice (pipa berlobang, mudah tertutup dengan mikroba), spargernozzel (pipa terbuka atau tertutup dibawah impeller) (Ariyanto, Arifin, \& Ilyas, 2011).

\section{METODE PENELITIAN}

Metode penelitian ini terdiri dari beberapa tahapan, seperti yang diperlihatkan pada Gambar 1. Tahapan terpenting dari penelitian yang dilakukan ada pada tahap analisa perancangan, dimana ditujukan untuk memastikan rancangan yang telah dibuat sesuai kebutuhan yang diperlukan.

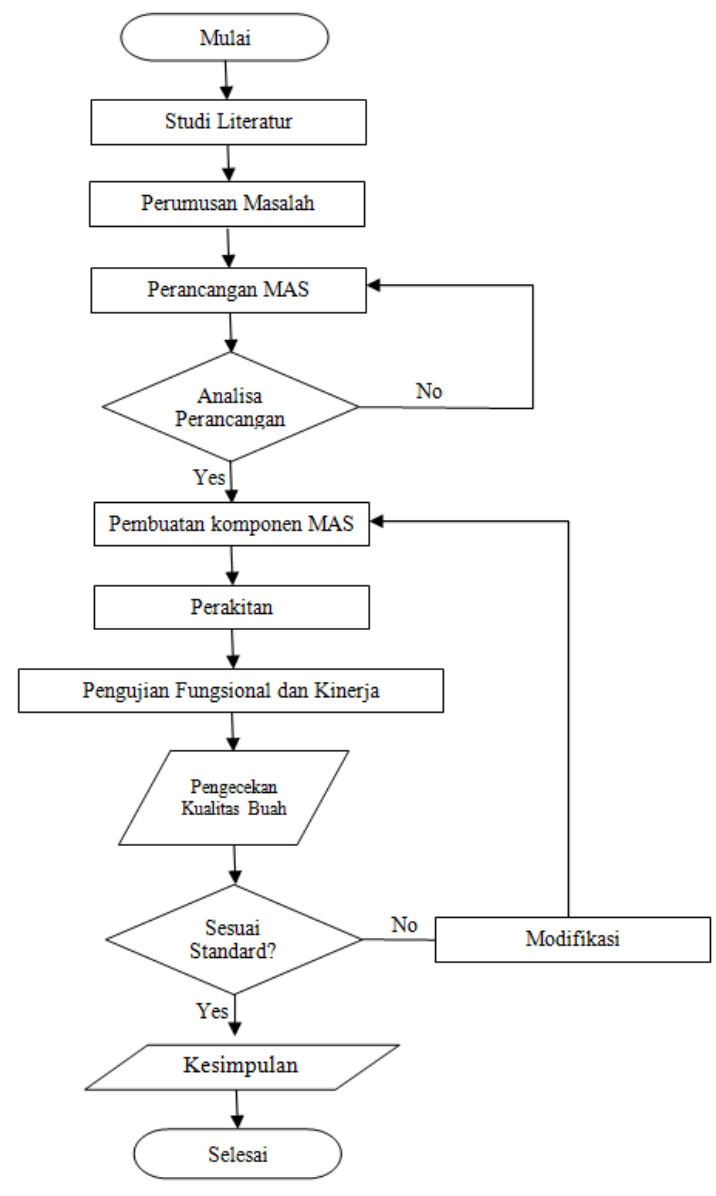

Gambar 1. Metode penelitian

Kemudian proses perhitungan menentukan apakah rancangan dapat lanjut ke tahapan selanjutnya atau tidak. Rancangan dinyatakan lanjut jika analisa rancangan sudah sesuai kebutuhan, baik dari kekuatan rangka dan aliran yang dihasilkan, dan rancangan akan kembali pada tahapan Perancangan MAS bila rancangan dikatakan tidak lanjut tahapan selanjutnya. Tahap pembuatan komponenkomponen untuk Teknologi MAS terdiri dari proses permesinan seperti pemotongan, perlubangan, dan penghalusan. Sedangkan tahap perakitan ditujukan untuk menyambung dan memasang seluruh komponen menjadi satu kesatuan teknologi MAS. Menyambung dan memasang komponen dilakukan dengan metode pengelasan serta metode penyambungan mur dan baut.

Tahap pengujian yang dilakukan adalah pengujian fungsional dan pengujian kinerja. Pengujian fungsional dilakukan untuk melihat kesesuaian fungsi dari tiap komponen dengan parameternya. Pengujian kinerja dilakukan untuk melihat penurunan kadar oksigen dan kadar glukosa pada buah pisang. Untuk pengecekan kualitas buah, dalam hal ini adalah pisang ambon, yang diuji adalah kadar glukosa untuk mengukur tingkat kematangannya.

\section{HASIL DAN PEMBAHASAN \\ a. Perancangan dan Pengembangan Produk}

Spesifikasi teknologi yang didapatkan berdasarkan hasil rekapitullasi pengisian quisioner yang ditujukan untuk umum dengan hasil seperti pada Tabel 1. Sedangkan untuk pemilihan konsep produk dilakukan dengan menilai konsep dari beberapa metode teknologi pengawetan dengan hasil seperti yang ditunjukkan pada Tabel 2 dan Gambar 2.

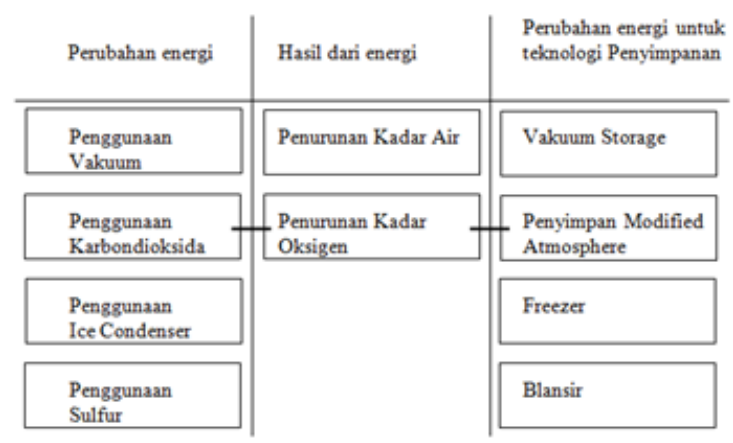

Gambar 2. Skema konsep terpilih

Konsep yang dipilih selanjutnya dibuat gambaran konsepnya untuk dapat dibuat rancangan desain produknya seperti yang diperlihatkan pada Gambar 3. Gambar 4, memperlihatkan skema sistem kerja atau 
Wina Libyawati, Agri Suwandi, Hafidan Agustian : Rancang Bangun Teknologi Modified Atmosphere Storage (Mas) Dengan Kapasitas $4,77 \mathrm{M}^{3}$

Jurnal Teknologi 9 (2) pp 103- 116 @ 2017

fungsi teknologi MAS yang saling terkait

untuk menghasilkan produk yang optimal.

Tabel 1. Spesifikasi kebutuhan

\begin{tabular}{|c|c|c|c|}
\hline No. & Metrik & Unit & Nilai \\
\hline 1 & Sumber energi & jenis energi & listrik dan gas \\
\hline 2 & Ruang penyimpanan besar & barrel unit & $4,8 \mathrm{~m} 3$ \\
\hline 3 & Dinding ruang kuat & $\begin{array}{l}\text { jenis material berdasarkan } \\
\text { nilai kekerasan dan korosi }\end{array}$ & - \\
\hline 4 & Biaya pembuatan produk terjangkau & Rupiah & $<$ Rp. 10.000 .000 \\
\hline 5 & Harga komponen dan material terjangkau & Rupiah & $<$ Rp. 8.000 .000 \\
\hline 6 & Pengoperasian yang mudah & tingkat kesulitan & mudah \\
\hline 7 & Kinerja produk & $\begin{array}{l}\text { presentasse penurunan } \\
\text { kadar oksigen }\end{array}$ & hingga dibawah $10 \%$ \\
\hline 8 & Perawatan dan perbaikan yang mudah & tingkat kesulitan & mudah \\
\hline 9 & Awet & masa ketahanan minimal & 7 tahun \\
\hline 10 & Pengaplikasian dilakukan pada berbagai makanan & jenis makanan & buah-buahan dan sayur-sayuran \\
\hline
\end{tabular}

Tabel 2. Pemilihan konsep

\begin{tabular}{|c|c|c|c|c|}
\hline \multirow[b]{2}{*}{ Kriteria Pemilihan } & \multicolumn{4}{|c|}{ Konsep } \\
\hline & $\begin{array}{c}\text { A } \\
\text { Vakum }\end{array}$ & $\begin{array}{c}\text { B } \\
\text { MAS }\end{array}$ & $\begin{array}{c}\text { C } \\
\text { Freezer }\end{array}$ & $\begin{array}{c}\text { D } \\
\text { Blansir }\end{array}$ \\
\hline Mudah dalam pengoperasian & + & 0 & + & - \\
\hline Mudah perawatan dan perbaikan & 0 & + & - & + \\
\hline Mudah dalam pembuatan & 0 & + & - & + \\
\hline Mudah dalam pemngaturan & + & 0 & + & 0 \\
\hline Efektif menurunkan oksigen & - & 0 & - & + \\
\hline Efektif menurunkan kadar air & + & - & 0 & 0 \\
\hline Hasil Pengujian & - & + & 0 & - \\
\hline Jumlah + & 3 & 3 & 2 & 3 \\
\hline Jumlah 0 & 2 & 3 & 2 & 1 \\
\hline Jumlah - & 2 & 1 & 3 & 3 \\
\hline Skor & 1 & 2 & -1 & 0 \\
\hline Ranking & 2 & 1 & 4 & 3 \\
\hline Dilanjutkan? & Tidak & $\mathrm{Ya}$ & Tidak & Tidak \\
\hline
\end{tabular}


Tabel 3. Tabel penilaian industri

\begin{tabular}{lll}
\hline Kategori & \multicolumn{1}{c}{$\begin{array}{c}\text { Tingkat Kepentingan } \\
\text { Sedang }\end{array}$} \\
\hline Kualitas & $\begin{array}{l}\text { Penggunaan metode dapat memperpanjang } \\
\text { ketahanan buah hingga } 3 \text { minggu. Produk } \\
\text { dapat bertahan hingga } 8 \text { tahun. }\end{array}$ \\
Perawatan dan & $\begin{array}{l}\text { Tampilan produk sederhana, berbentuk kubu: } \\
\text { dan ruang simpan berbahankan kayu }\end{array}$ \\
Perbaikan & $\begin{array}{l}\text { Perawatan dan perbaikan pada produk mudal } \\
\text { dan pembelian komponen produk murah bila } \\
\text { terdapat kerusakan pada komponen produk }\end{array}$ \\
Perbedaan Produk & $\begin{array}{l}\text { Penggunaan produk mudah karena hanya } \\
\text { dengan mengatur tekanan udara kompresor } \\
\text { dan tekanan gas pada regulator. Aman dalam } \\
\text { penggunaannya }\end{array}$ \\
\hline
\end{tabular}

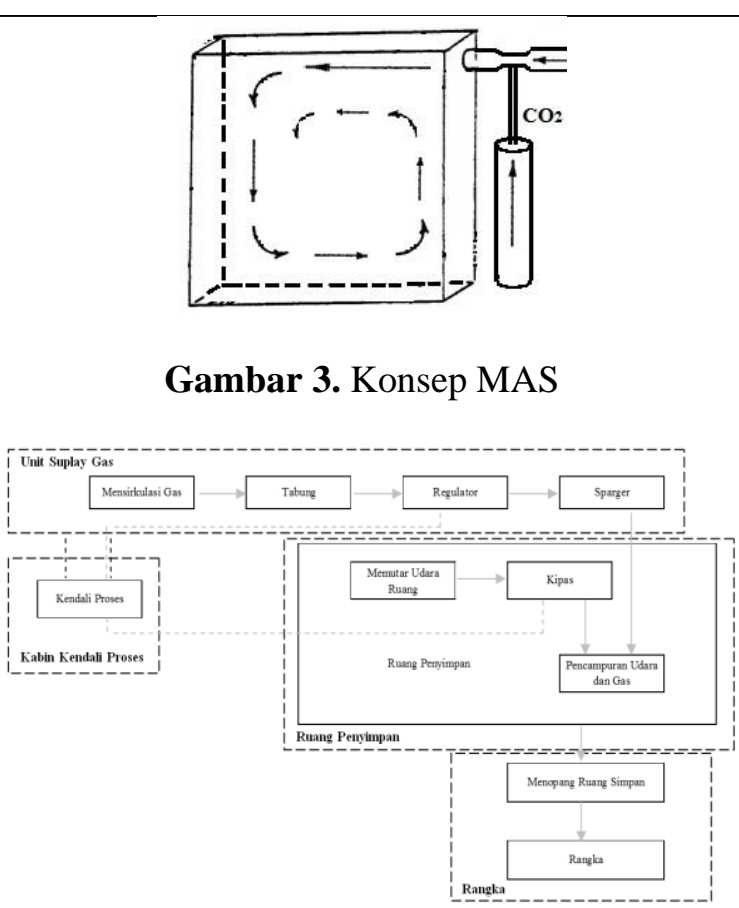

Gambar 4. Skema fungsi produk
Desain industri diawali dengan penilaian industri yang berfungsi untuk menentukan batasan dalam dalam pmbuatan dan produk seperti pada Tabel 3. Sedangkan DFM digunakan untuk menghituung biaya upah dalam pembuatan komponen produk berdasarkan waktu yang digunakan (Tabel 4). Untuk waktu yang didapat akan dikalikan dengan Upah Minimum Regional Jakarta, yaitu Rp.3.355.750,00 / bulan (PP Nomor 78, Tahun 2015), maka dalam satuan detik didapat Rp.5,83. Sehingga dihasilkan upah jasa pembuatan MAS yang diberikan dapat dilihat pada Tabel 5.

Prototipe MAS memiliki kapasitas ruang 4,77 $\mathrm{m}^{3}$. Ruang MAS dapat diisi delapan sampai sepuluh buah tandan pisang, digantung pada dua buah tiang dalam ruang MAS. Dimensi total teknologi MAS panjang $2020 \mathrm{~mm}$ x lebar $1870 \mathrm{~mm} x$ tinggi $1870 \mathrm{~mm}$. Rangka MAS dibuat dari besi siku dengan dimensi $50 \mathrm{~mm} x$ $50 \mathrm{~mm}$ dan tebal $4 \mathrm{~mm}$. Dinding MAS berbahankan lebar PVC dengan tebal $5 \mathrm{~mm}$ (lihat Gambar 5). 
Tabel 4. Waktu pembuatan

\begin{tabular}{ccccc}
\hline \multirow{2}{*}{ No. } & \multirow{2}{*}{ Nama Komponen } & \multicolumn{3}{c}{ Waktu Proses Permesinan (detik) } \\
& & Pemotongan & Perlubangan & Pengelasan \\
\hline 1 & Rangka & 600 & 192 & 1060 \\
2 & Dudukan & 100 & & 355 \\
3 & Poros & 110 & & \\
4 & Lembar PVC & 1032 & 192 & 10322 \\
5 & Pipa & 192 & & 5130 \\
\hline
\end{tabular}

Tabel 5. Upah pembuatan produk

\begin{tabular}{ccc}
\hline No. & Nama Komponen & $\begin{array}{c}\text { Biaya per Komponen } \\
\text { (Rp.) }\end{array}$ \\
\hline 1 & Rangka & 10797,16 \\
2 & Dudukan & 2652,65 \\
3 & Poros & 641,3 \\
4 & Lembar PVC & 67313,18 \\
5 & Pipa & 313027,26 \\
\hline & Total Biaya & 112431,55 \\
\hline
\end{tabular}
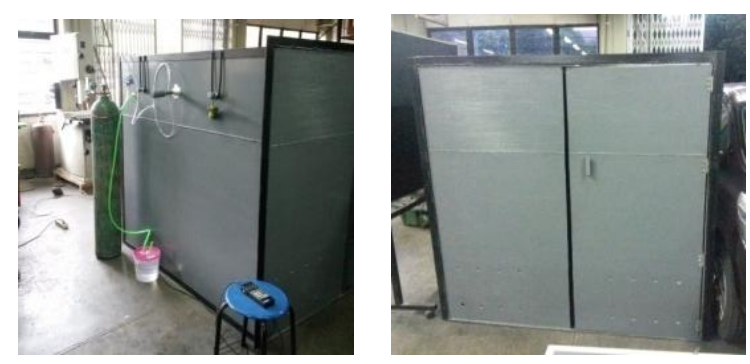

Gambar 5. Prototipe produk MAS

Proyek pengembangan teknologi MAS dilihat dari segi ekonomi untuk merekapitulasi biaya bulanan dan tahunan. Segi ekonomi didasarkan dari data-data sebagai berikut:

1. Biaya Pengembangan (Rp.6.000.000)

2. Biaya Percepatan (Rp.2.000.000)

3. Biaya Pemasaran dan Bantuan (Rp.1.500.000/thn)

4. Biaya Produksi (Rp.5.000.000/unit)

5. Volume Penjualan (16 unit/thn)

6. Harga Unit (Rp.6.000.000)
Berdasarkan data tersebut, selanjutnya dihitung agar dapat data penjualan tiap tahun dan prediksi modal akan kembali. Biaya pengembangan dikeluarkan pada tahun pertama proyek. Biaya percepatan dikeluarkan sebelum produk mulai dipasarkan. Setelah dipasarkan, proyek akan dikenakan biaya pemasaran dan bantuan. Berdasarkan data pada Tabel 6, didapatkan surplus sebesar Rp.2.700.000 yang didapat pada tahun ke-2 quartal ke-4.

Tabel 7, memperlihatkan jadwal proyek dalam satu tahun sebelum produk mulai dipasarkan. Data tersebut digunakan untuk pembagian waktu kerja untuk tiap bagian yang berperan penting dalam proyek pembuatan teknologi MAS.

Sedangkan pada Tabel 8, diperlihatkan data pembagian waktu yang ditetapkan dalam satuan persen (\%) untuk setiap bulannya dalam satu tahun awal. 
Tabel 6. Prediksi kas tahunan

\begin{tabular}{|c|c|c|c|c|c|c|c|c|c|c|c|c|}
\hline \multirow{2}{*}{ (Rp. -000$)$} & \multicolumn{4}{|c|}{ Tahun 1} & \multicolumn{4}{|c|}{ Tahun 2} & \multicolumn{4}{|c|}{ Tahun 3} \\
\hline & Q1 & Q2 & Q3 & Q4 & Q1 & Q2 & Q3 & Q4 & Q1 & $\mathrm{Q} 2$ & Q3 & $\mathrm{Q} 4$ \\
\hline Biaya pengembangan & -1500 & -1500 & -1500 & -1500 & & & & & & & & \\
\hline Biaya percepatan & & & & -1000 & -1000 & & & & & & & \\
\hline Biaya pemasaran dan bantuan & & & & & -325 & -325 & -325 & -325 & -325 & -325 & -325 & -325 \\
\hline Biaya produksi & & & & & & -20000 & -20000 & -20000 & -20000 & -20000 & -20000 & -20000 \\
\hline Volume produksi & & & & & & 4 & 4 & 4 & 4 & 4 & 4 & 4 \\
\hline Biaya produksi unit & & & & & & -5000 & -5000 & -5000 & -5000 & -5000 & -5000 & -5000 \\
\hline Pendapatan penjualan & & & & & & 24000 & 24000 & 24000 & 24000 & 24000 & 24000 & 24000 \\
\hline Volume penjualan & & & & & & 4 & 4 & 4 & 4 & 4 & 4 & 4 \\
\hline Harga unit & & & & & & 6000 & 6000 & 6000 & 6000 & 6000 & 6000 & 6000 \\
\hline Kas per Periode & -1500 & -1500 & -1500 & -2500 & -1325 & 3675 & 3675 & 3675 & 3675 & 3675 & 3675 & 3675 \\
\hline Total & -1500 & -3000 & -4500 & -7000 & -8325 & -4650 & -975 & 2700 & 6375 & 10050 & 13725 & 17400 \\
\hline
\end{tabular}

Tabel 7. Jadwal proyek

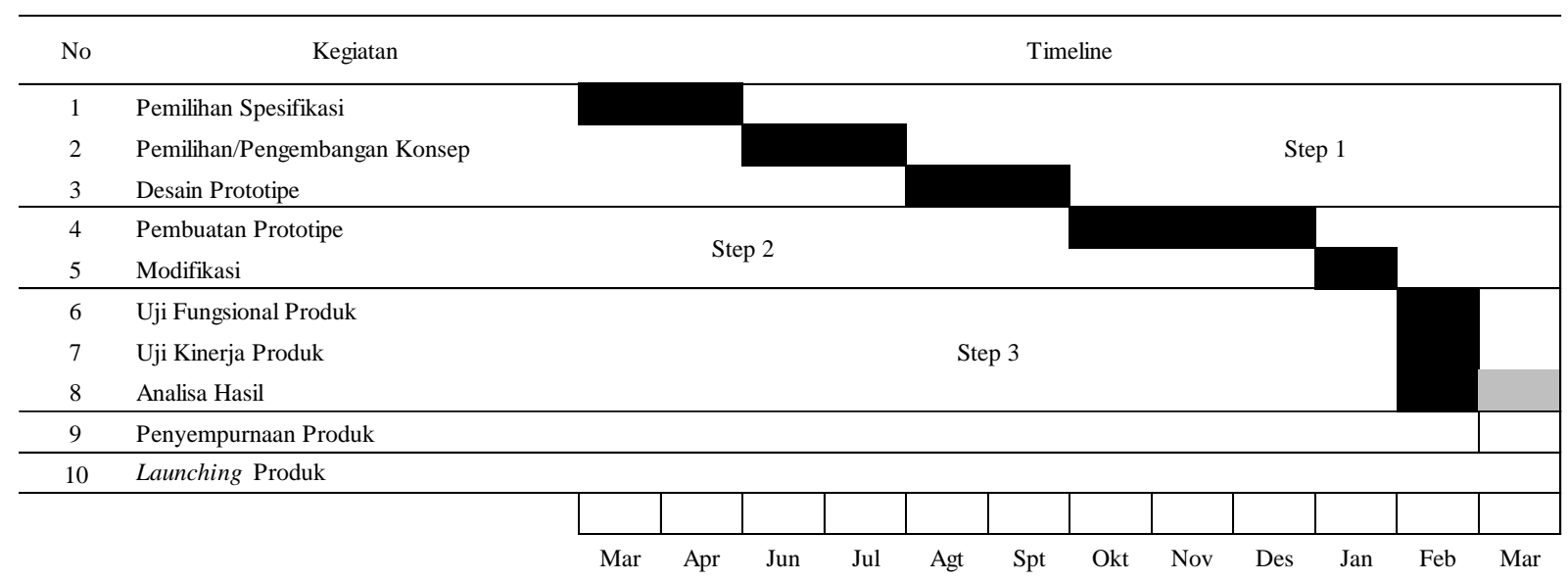

Tabel 8. Pembagian waktu tiap divisi

\begin{tabular}{|c|c|c|c|c|c|c|c|c|c|c|c|c|}
\hline \multirow{2}{*}{ Bagian } & \multicolumn{11}{|c|}{ Bulan } & \multirow[b]{2}{*}{ Mar } \\
\hline & Mar & Apr & Jun & Jul & Agt & Spt & Okt & Nov & Des & Jan & Feb & \\
\hline Kepala Proyek & 100 & 100 & 100 & 100 & 100 & 100 & 100 & 100 & 100 & 100 & 100 & 100 \\
\hline Koordinator Jadwal & 25 & 25 & 25 & 25 & 25 & 25 & 25 & 25 & 25 & 25 & 25 & 25 \\
\hline Bagian Desain I & 25 & 25 & 50 & 75 & 100 & 100 & 75 & 50 & 75 & 100 & 75 & \\
\hline Bagian Desain II & & & & 75 & 100 & 100 & 75 & & 75 & 100 & 75 & \\
\hline Bagian Pembuatan I & & & & & 50 & 75 & 100 & 100 & 100 & 100 & 100 & 75 \\
\hline Bagian Pembuatan II & & & & & & 75 & 100 & 100 & 100 & 100 & 75 & \\
\hline Bagian Perbaikan & & & & & & & & 75 & 100 & 100 & 100 & 75 \\
\hline Bagian Quality Control & & & & & & & & & 75 & 100 & 100 & 75 \\
\hline Bagian Analisa Makanan & & & & & & & & & & & 100 & \\
\hline Bagian Pemasaran & 25 & 25 & 25 & 25 & 25 & 25 & 25 & 25 & 25 & 50 & 75 & 100 \\
\hline
\end{tabular}

\section{b. Pembuatan dan Perakitan MAS}

Berikut adalah tahapan yang dilakukan dalam pembuatan komponen dan perakitan teknologi MAS:

1. Pembuatan dan perakitan rangka:

1) Pengukuran 12 batang besi siku dengan panjang awal $2000 \mathrm{~mm}$
2) Pemotongan tiap besi siku menjadi panjang $1730 \mathrm{~mm}$

3) Periksa kembali ukuran besi siku yang telah dipotong

4) Sambung 4 batang besi siku dengan las listrik menjadi bentuk persegi untuk rangka bagian bawah. 
5) Sambung 4 batang besi siku dengan las listrik untuk rangka sisi (kanan 2 batang dan kiri 2 batang).

6) Sambung 4 batang besi siku dengan las listrik menjadi bentuk persegi untuk rangka atas. (terpisah dari rangka sisi).

7) Sambung rangka atas dengan rangka sisi dengan las listrik.

2. Pembuatan dan perakitan dudukan tiang:

1) Pengukuran besi diameter $10 \mathrm{~mm}$ dengan panjang awal $2000 \mathrm{~mm}$.

2) Pemotongan besi menjadi 4 batang dengan panjang $500 \mathrm{~mm}$.

3) Periksa kembali ukuran tiap panjang besi.

4) Lekukkan tiap besi $360^{\circ}$.

5) Sambung dudukan tiang gantung dengan rangka atas bagian kiri dan kanan (2 kanan dan 2 kiri) dengan las listrik.

3. Pembuatan dan perakitan dinding PVC:

Dinding PVC tidak dapat dijadikan dari satu lembar PVC karena ukuran awal lembar PVC adalah $2440 \mathrm{~mm} \times 1220 \mathrm{~mm}$, maka dinding PVC terdiri dari 4 sisi dengan 2 sambungan dan 2 sisi dengan 3 sambungan. Berikut tahapan pembuatan dan perakitan dinding PVC:

1) Pengukuran lembaran PVC.

2) Pemotongan lembar PVC sesuai dengan yang ditentukan.

3) Periksa kembali ukuran-ukuran yang ada sebelum disambung

4) Sambung lembaran PVC ukuran $1220 \mathrm{~mm} \times 1720 \mathrm{~mm}$ dan 500 mm x $1720 \mathrm{~mm}$ untuk menjadi dinding sisi bawah dengan las PVC.

5) Sambung lembaran PVC ukuran $1220 \mathrm{~mm} \times 1720 \mathrm{~mm}$ dan 500 $\mathrm{mm} \times 1720 \mathrm{~mm}$ untuk menjadi dinding sisi kanan dengan las PVC.

6) Sambung lembaran PVC ukuran $1220 \mathrm{~mm} \times 1720 \mathrm{~mm}$ dan 500 mm x $1720 \mathrm{~mm}$ untuk menjadi dinding sisi kiri dengan las PVC.

7) Lubangi dinding PVC sisi kanan dan sisi kiri untuk lubang tiang gantung.
8) Sambung lembaran PVC ukuran $1220 \mathrm{~mm} \times 1720 \mathrm{~mm}$ dan 500 $\mathrm{mm} \times 1720 \mathrm{~mm}$ untuk menjadi dinding sisi depan dengan las PVC.

9) Lubangi dinding PVC sisi kanan, kiri, belakang dan atas untuk lubang sparger.

10) Potong dinding PVC depan dengan ukuran $1720 \mathrm{~mm}$ x 800 mm untuk dijadikan pintu.

11) Sambung 3 lembaran PVC ukuran $1220 \mathrm{~mm}$ x $1720 \mathrm{~mm}, 500 \mathrm{~mm}$ x $1300 \mathrm{~mm}$ dan $500 \mathrm{~mm} \times 420 \mathrm{~mm}$ untuk menjadi dinding sisi belakang dengan las PVC.

12) Sambung 3 lembaran PVC ukuran $1220 \mathrm{~mm} \times 1720 \mathrm{~mm}, 500 \mathrm{~mm} \times$ $1300 \mathrm{~mm}$ dan $500 \mathrm{~mm} \times 420 \mathrm{~mm}$ untuk menjadi dinding sisi atas dengan las PVC.

13) Sambung dinding PVC sisi bawah (yang terpasang pada rangka bawah) dengan dinding PVC sisi kanan, kiri, depan dan belakang dengan las PVC.

14) Sambung dinding PVC sisi atas dengan dinding PVC yang telah terpasang dengan las PVC.

15) Lubangi rangka, dinding PVC sisi kanan dan pintu dengan bor listrik untuk pemasangan engsel pintu.

16) Pasang engsel pintu terhadap pintu dengan baut dan mur.

4. Pembuatan dan perakitan tiang gantung:

1) Pengukuran 2 batang besi hollow dengan panjang awal $2000 \mathrm{~mm}$.

2) Pemotongan tiap besi hollow menjadi panjang $1750 \mathrm{~mm}$.

3) Periksa kembali ukuran besi siku yang telah dipotong.

4) Pasang tiap tiang di lubang pada dinding PVC dan dengan tahan pada dudukan.

5. Pembuatan dan perakitan sparger:

1) Sambung reducer dengan pipa menggunakan lem pipa.

2) Perlubangan dan menembus bagian tengah sparger untuk nipple.

3) Pembuatan ulir pada dua lubang yang dibuat.

4) Pasang nipple pada lubang. 
5) Tutup sambungan pada sisi reducer.

6) Pasang pada lubang-lubang yang telah disediakan di dinding-dinding PVC.

\section{c. Pengujian Teknologi}

\section{Uji Fungsional}

Uji fungsional digunakan untuk menguji kesesuaian fungsi pada pada teknologi. Berikut alat dan bahan yang digunakan saat proses uji fungsional (Gambar 6):

1) Teknologi MAS.

2) Tabung Karbondioksida

3) Selang

4) Manifold

5) Oksigenmeter

6) Alat ukur suhu ruang

7) Alat ukur suhu tembak infra merah

8) Wadah berisi air (sebagai tempat keluar oksigen)

9) Kipas didalam ruang MAS

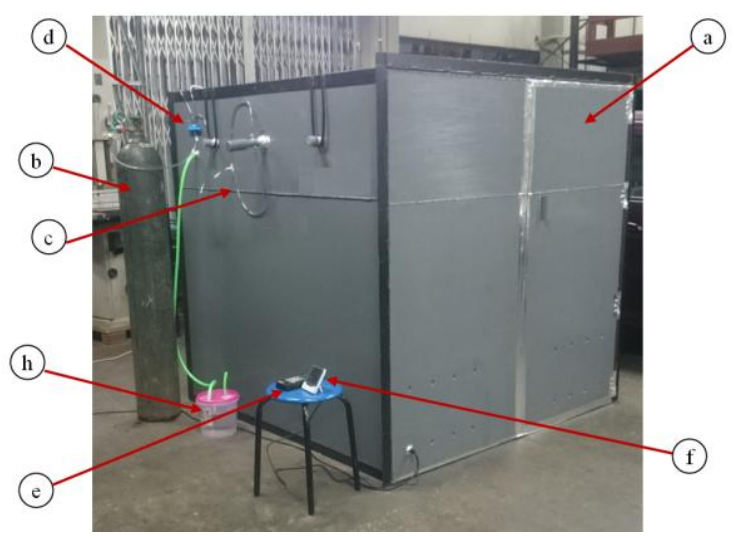

Gambar 6. Sistem pengujian MAS

Prosedur uji fungsional dilakukan sebagai berikut:

1) Pasang selang yang terhubung dari regulator ke sparger.

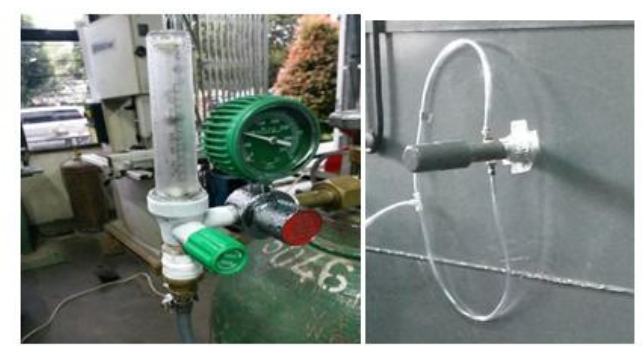

Gambar 7. Pemasangan selang regulator pada sparger

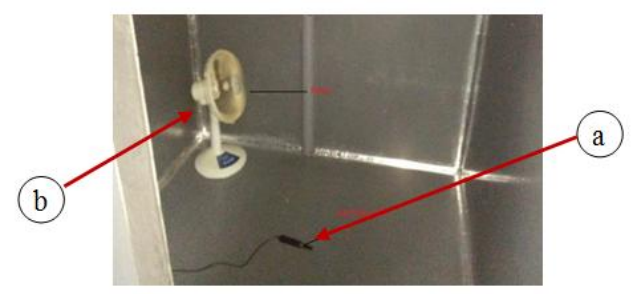

Gambar 8. (a) Posisi kipas (b) Indikator oksigen

2) Pasang indikator oksigen meter didalam ruang MAS.

3) Menyalakan kipas didalam ruang MAS.

4) Pasang wadah berisi air yang terhubung dengan selang ke dalam ruang MAS.

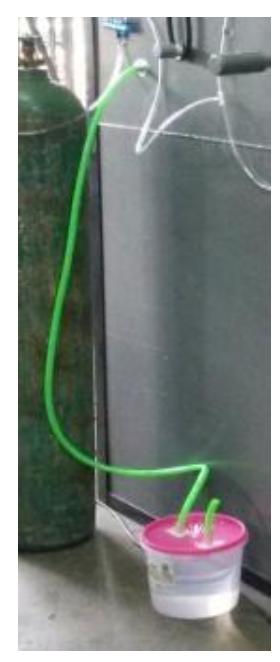

Gambar 9. Posisi wadah air

5) Mengunci ruang MAS agar tidak terjadi kebocoran.

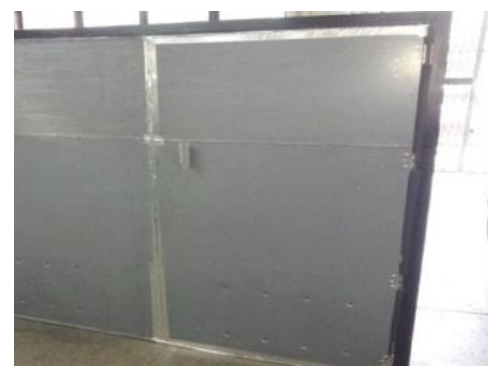

Gambar 10. Kondisi pintu yang tersegel 
6) Membaca dan mencatat indikator dari setiap alat ukur untuk nilai keadaan awal.

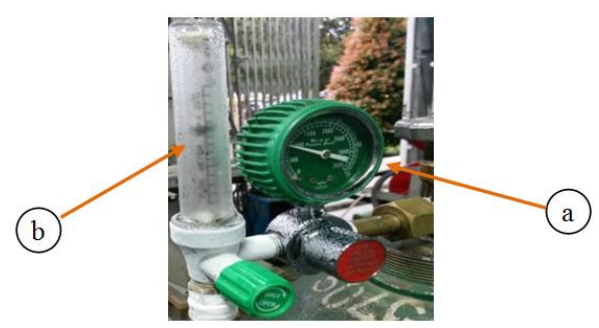

Gambar 11. (a) Pembukaan klep tabung (b) Pengaturan debit $\mathrm{CO}_{2}$

7) Membuka penuh klep tabung karbon dioksida.

8) Mengatur debit karbon dioksida 5 liter/menit pada regulator.

9) Pembacaan alat ukur dilakukan setiap jam sekali.

10) Tutup klep tabung karbon dioksida setelah indikator oksigen mencapai dibawah $10 \%$.

\section{Uji Kinerja}

Uji kinerja digunakan untuk menguji hasil sesuai harapan atau tidak. Dalam kasus penelitian ini, yang diuji adalah kadar glukosa buah pisang, karena kadar glukosa pisang adalah parameter dari kematangan buah pisang.
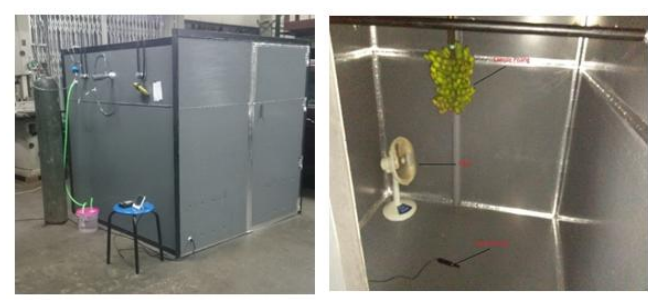

Gambar 12. Uji kinerja MAS

Alat dan bahan yang digunakan saat proses uji fungsional:

1) Teknologi MAS

2) Tabung karbon dioksida

3) Selang

4) Manifold

5) Oksigenmeter

6) Alat ukur suhu ruang
7) Alat ukur suhu tembak infra merah

8) Wadah berisi air (sebagai tempat keluar oksigen)

9) Kipas angin

10) Satu tandan pisang ditaruh didalam ruang MAS.

11) Satu buah pisang (diambil dari tandan sebelumnya) ditaruh diluar ruang MAS sebagai pembanding.

Prosedur uji fungsional dilakukan sebagai berikut:

1) Pasang selang yang terhubung dari regulator ke sparger.

2) Pasang indikator oksigenmeter didalam ruang MAS.

3) Pasang wadah berisi air yang terhubung dengan selang ke dalam ruang MAS.

4) Meletakkan satu tandan pisang dengan cara digantung pada tiang gantung.

5) Mengunci ruang MAS agar tidak terjadi kebocoran.

6) Taruh satu buah pisang diluar ruang MAS sebagai pembanding.

7) Membaca dan mendata indikator dari setiap alat ukur untuk nilai keadaan awal.

8) Membuka penuh klep tabung karbondioksida.

9) Mengatur debit karbondioksida 5 liter/menit pada regulator.

10) Pembacaan alat ukur dilakukan setiap jam sekali sampai indikator kadar oksigen dibawah $10 \%$.

11) Tutup klep tabung karbondioksida dan biarkan buah pisang didalam ruang MAS selama 24 jam penuh.

12) Buka ruangan dan biarkan kadar oksigen naik sampai titik aman $(19,5 \%-22 \%)$ untuk masuk ruang MAS dan memetik sebuah pisang yang akan diuji.

13) Buah pisang tersebut dan buah pisang pembanding (luar ruang MAS) selanjutnya akan diuji kadar glukosa. 
Tabel 9. Hasil uji fungsional

\begin{tabular}{|c|c|c|c|}
\hline No. & Nama Komponen & Parameter & Status \\
\hline 1 & Ruang MAS & Kedap dan tidak lendut & Berfungsi \\
\hline 2 & Regulator & Tekanan dan debit & Berfungsi \\
\hline 3 & Selang & Perubahan suhu & Berfungsi \\
\hline 4 & Oksigenmeter & Kalibrasi angka ukur & Berfungsi \\
\hline 5 & Alat ukur suhu & Kalibrasi angka ukur & Berfungsi \\
\hline 6 & Alat ukur kelembapan & Kalibrasi angka ukur & Berfungsi \\
\hline
\end{tabular}

Tabel 10. Hasil uji kinerja

\begin{tabular}{ccccc}
\hline No. & $\begin{array}{c}\text { Posisi Pisang terhadap Ruang } \\
\text { MAS }\end{array}$ & Warna & Tekstur & $\begin{array}{c}\text { Rasa } \\
\text { (kadar glukosa \%) }\end{array}$ \\
\hline 1 & Didalam & $\begin{array}{c}\text { Hijau dan sedikit bintik } \\
\text { hitam } \\
\text { Kuning dan banyak } \\
\text { bintik hitam }\end{array}$ & Keras & Sedikit lunak \\
2 & Diluar & & 9,33 \\
\hline
\end{tabular}


Hasil uji fungsional menyatakan fungsional tiap komponen pada MAS dapat berfungsi dengan baik. Adapun Komponen yang dapat mempengaruhi parameter kinerja MAS dapat dilihat pada Tabel 9. Pengujian dilanjutkan dengan uji kinerja. Uji kinerja dilakukan dengan menyimpan satu tandan buah pisang dan disuntikan karbondioksida selama 24 jam dan tanpa karbondioksida selama 24 jam setelahnya. Sedangkan hasil uji kinerja teknologi MAS pada buah pisang dapat dilihat pada Tabel 10. Hasil uji kinerja, juga dapat dilihat pada perubahan fisik yang terjadi pada buah pisang seperti pada Gambar 13 .

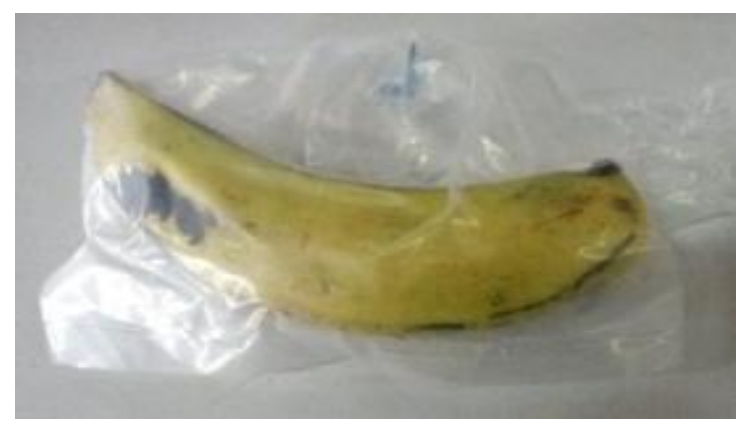

(a) Pisang di luar Ruang MAS

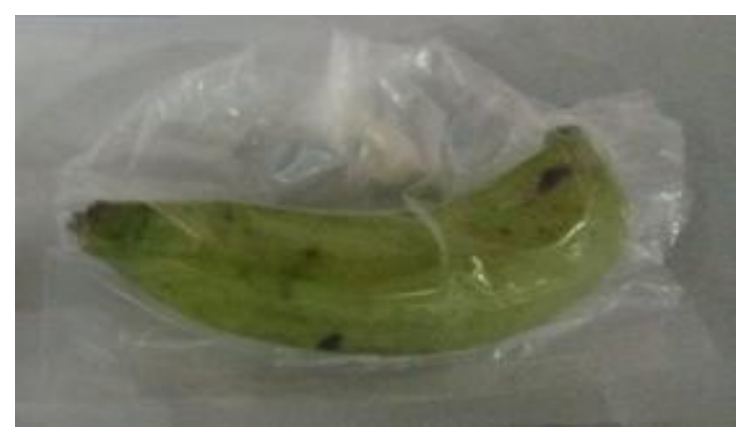

(b) Pisang di dalam Ruang MAS

Gambar 13. Pisang hasil uji kinerja MAS

\section{KESIMPULAN}

Kesimpulan dari hasil penelitian ini adalah teknologi MAS yang dirancang dan dibuat berdasarkan hasil uji kinerja menunjukkan buah pisang belum matang terlihat dari warna hijau dengan sedikit bintik hitam, tekstur keras dan memiliki kadar glukosa 5,33\% (kematangan buah pisang memiliki kadar glukosa $15 \%$ - 20\%). Artinya teknologi MAS ini berhasil dengan menghambat pisang menjadi cepat matang dengan waktu tahan 2 minggu.
Untuk memperkaya hasil validasi data yang optimal, maka diperlukan penelitian lanjut dengan menambah varian uji pisang dengan perbandingan teknologi pengawetan lain seperti Freezer dan Vacuum.

\section{DAFTAR PUSTAKA}

Anibal Concha-Meyer, J. D. 2015. Shelf Life Determination of Fresh Blueberries (Vaccinium corymbosum) Stored under Controlled Atmosphere and Ozone. International Journal of Food Science, 19.

Ariyanto, A., Arifin, S., dan Ilyas, M. 2011. Perancangan Sistem Pengendalian Level Deaerator Menggunakan Fuzzy Gain Scheduling-pi di PT. Petrowidada. Surabaya: Perpustakaan Institut Teknologi Sepuluh Nopember Surabaya.

Badran, A. M. 1969. Patent No. US 3450542 $A$. United States of America.

Barrios, S., P., L., dan F., M. 2014. Modelling passive modified atmosphere packaging of strawberries: Numerical analysis and model validation. International Food Research Journal, 507-515.

Caleb, O. J., Mohajon, P. V., dan Fahad AlJulanda Al-Said, U. L. 2013. Modified Atmosphere Packaging Technology of Fresh and Fresh-Cut produce and the microbial consequences-A Review. Food Bioprocess Technology, 303-329.

Kader, A. A. 2004. Controlled atmosphere storage. Agricultural, 66-76.

Khoshgozaran, S., dan Mohammad Hossein Azizi, W. B. 2012. Evaluating the effect of modified atmosphere packaging on cheese characteristics: a review. Dairy Science and Technology, 1-24.

Mahmoud Soultani, H. M. 2015. Modified Atmosphere Packaging; A Progressive Technology for Shelf-Life Extension of Fruits and Vegetables. Journal of Applied Packaging Research, 33-59.

Renu, R., \& V., C. D. 2013. Effect of Modified Atmosphere Storage Conditions on Biochemical Parameters of Bell Peppers. International Journal of Agriculture and Food Science Technology, 915-922. 
Rinaldi, M. 2016. Study and Optimization of a CO2 Sparger for Carbonated Beverages and Beer by Means of CFD Modeling. International Journal of Food Engineering, 867-873.

Rohani, M., Zaipun, M., dan Norhayati, M. 1997. Effect of modified atmosphere on the storage life and quality of Eksotika papaya. Journal of Tropical Agriculture and Food Science, 25, 103-114.

Sandhya, K. V. 2010. Modified Atmosphere Packaging of Fresh Produce: Current Status and Future Needs. LWT Food Science and Technology, 381-392.

Sari, D. A., dan Hadiyanto, H. 2013. Teknologi dan Metode Penyimpanan Makanan sebagai Upaya Memperpanjang Shelf
Life. Jurnal Aplikasi Teknologi Pangan, 2, 52-59.

Sidik, M. 2000. The Quality Changes of Rice Stored Under. Journal of Agricultural Technology, 1, 55-63.

Sudiari, N., dan Sutrisno. 1998. Pengkajian Karakteristik Penyimpanan Produk "Minimally Processed" Buah Nangka (Arthocarpus heterophyllus Lamk.). Buletin Keteknikan Pertanian, 12-21.

Ulrich, K. T., dan Eppinger, S. D. 2008. Product Design and Development (4nd ed.). McGrawHill.

Zenoonzian, M. S. 2011. Combined Effect of Packaging Method and Temperatur on the Leafy Vegetables Properties. International Journal of Environmental Science and Development, 1-4. 